\title{
Breast Cancer Metastasis Mimicking Osteomyelitis
}

\author{
Osteomiyeliti Taklit Eden Meme Kanseri Metastazı \\ ๑ Deniz Hancı, ๑ Onur Üstün*, ๑ Şelale Dinç** \\ Okmeydanı Training and Research Hospital, Clinic of Otorhinolaryngology, Istanbul, Turkey \\ *University of Health Sciences Turkey, Haseki Training and Research Hospital, Clinic of Otorhinolaryngology, Istanbul, Turkey \\ **Memorial Şişli Hastanesi, Clinic of Radiology, Istanbul, Turkey
}

\begin{abstract}
An 80-year-old woman with a history of breast cancer 16 years ago presented with malnutrition, swelling, and paresthesia of the right cheek. Computed tomography revealed diffuse osteosclerosis without lysis and adjacent soft tissue swelling on the right mandible. These radiological findings were more compatible with primary chronic osteomyelitis than metastasis from breast cancer, and biopsy was necessary for diagnosis. This report describes breast cancer metastasis mimicking primary chronic osteomyelitis 16 years after diagnosis and its differential diagnosis in the mandible.
\end{abstract}

Keywords: Osteomyelitis, breast cancer metastasis, mandibula

\section{Introduction}

Metastatic tumors are rare in the oral region. Metastatic lesions may occur in the bones of the jaw, in soft tissues of the oral cavity, or in both osseous and soft tissues. The mandible is one of the most frequent locations for metastases and, the most frequently involved site in the jaw bones is the molar area. This region is susceptible to the accumulation of neoplastic cells due to branching of local blood vessels, slowing of blood flow and the presence of hematopoietic bone marrow. Diagnosis of metastatic lesions is challenging due to their rarity and their atypical clinical and radiographic appearance. Since the most common symptom in the jaw is pain, these lesions can be misdiagnosed as pathological entities of dental origin (1).

Metastatic tumors of the oral cavity do not show a pathognomonic radiographic sign, and radiographic examination is therefore rarely diagnostically important. Although most patients have been previously diagnosed
On altı yıl önce geçirilmiş meme kanseri hikayesi mevcut olan 80 yaşındaki hasta malnütrisyon, sağ yanağın şişmesi ve parestezisiyle başvurdu. Bilgisayarlı tomografide sağ mandibulada lizis bulunmayan osteoskleroz ve komşu dokularda şişlik izlendi. Bu radyolojik bulgular meme kanseri metastazından çok primer kronik osteomiyelit ile uyumluydu. Tanı için biyopsi alındı. Bu olgu sunumunda 16 yıl önce geçirilmiş meme kanserinden mandibulaya primer kronik osteomiyeliti taklit eden metastaz olgusu sunulmuştur.

Anahtar Sözcükler: Osteomiyelit, meme kanseri metastazı, mandibula with primary neoplasms and treated, the first clinical sign of the malignancy is seen in the oral region in one third of metastases (2).

Patients with metastases in the jaw show various clinical symptoms and signs, which are swelling, pain, paresthesia of the lip, halitosis, loose or extruded teeth, gum irritation, regional lymphadenopathy, trismus, mandibular nerve involvement and numb chin syndrome (NCS), ulceration, cortical expansion of the jaw bones, and exophytic growth (1). Paresthesia or numbness of the chin and lower lip are important signs of metastatic tumors (2).

The clinical presentation resembles frequent pathological conditions, such as inflammatory hyperplasia, toothache, temporomandibular joint pain, osteomyelitis, periodontal conditions, trigeminal neuralgia, pyogenic granuloma, or giant cell granuloma, and therefore, the diagnosis of such cases can be difficult.

In the early stages of the disease, the lesion may not present a radiographic sign. In the analysis of Hirshberg et al. (2) with 390 metastatic tumors of the jaw, they found 
that $5.4 \%$ of the tumors did not show any important radiographic changes.

Diagnosis is made more difficult compared to cases of acute and secondary chronic osteomyelitis because of the clinical appearance and clinical course of primary chronic osteomyelitis. There is no predisposing event, such as an oral surgical procedure or an infected tooth. Clear signs of infection, such as the occurrence of a pus or fistula, are lacking.

This report describes breast cancer metastasis mimicking primary chronic osteomyelitis 16 years after diagnosis and its differential diagnosis in the mandible.

\section{Case}

An 80-year-old female with a history of breast cancer 16 years ago was admitted to our ear nose and throat clinic with the complaints of feeding difficulty, fatigue and subtle pain in the area of right mandibular molar parts. She had numbness for 3 years and swelling on the right side of the cheek for 1 year. The medical anamnesis revealed that the patient was operated (modified radical mastectomy with axillary lymph node dissection) 16 years ago for breast carcinoma of the right breast. After operation, the patient did not take radiotherapy or chemotherapy. The patient did not receive bisphosphatase treatment. She had visited her physician 5 years periodically for annual examination. Her medical history included hypertension and diabetes, and there was no history of alcohol or tobacco use. Clinical examination was difficult because of severe trismus. On intra-oral examination, diffuse swelling that was hard on palpation was observed on the right half of the mandible. Movement of the jaw was restricted. There was severe pain over the right half of the face and paresthesia of the chin and lower lip. Regional lymph nodes were not palpable.

Axial and serial $1 \mathrm{~mm}$-thick cross-sectional images obtained from cone beam computed tomography (CT) showed small radiolucent areas in close proximity to the third molar (Figure 1) that were not diagnostic of metastases. Magnetic resonance imaging (MRI) provided the most accurate view of a chronic osteomyelitis lesion in the right mandible (Figure 2).

Incisional biopsies were taken under local anesthesia from the mandible and sent to the pathology laboratory.

Formalin-fixed, paraffin-embedded five micron-thick tissue sections were stained with hematoxylin and eosin. The neoplastic cells contained abundant eosinophilic cytoplasm and large, darkly stained, pleomorphic nuclei (Figure 3). Several mitoses including atypical forms and minimal lymphoplasmacytoid inflammatory infiltration of the stroma were observed. The diagnosis was consistent with metastatic carcinoma of breast origin. Slides from the primary breast lesion were not available to compare with the metastatic focus.

For further treatment, the patient was referred to an oncologist, but the patient refused treatment. Written informed consent was obtained from the patient. The patient died of her disease 6 month later.

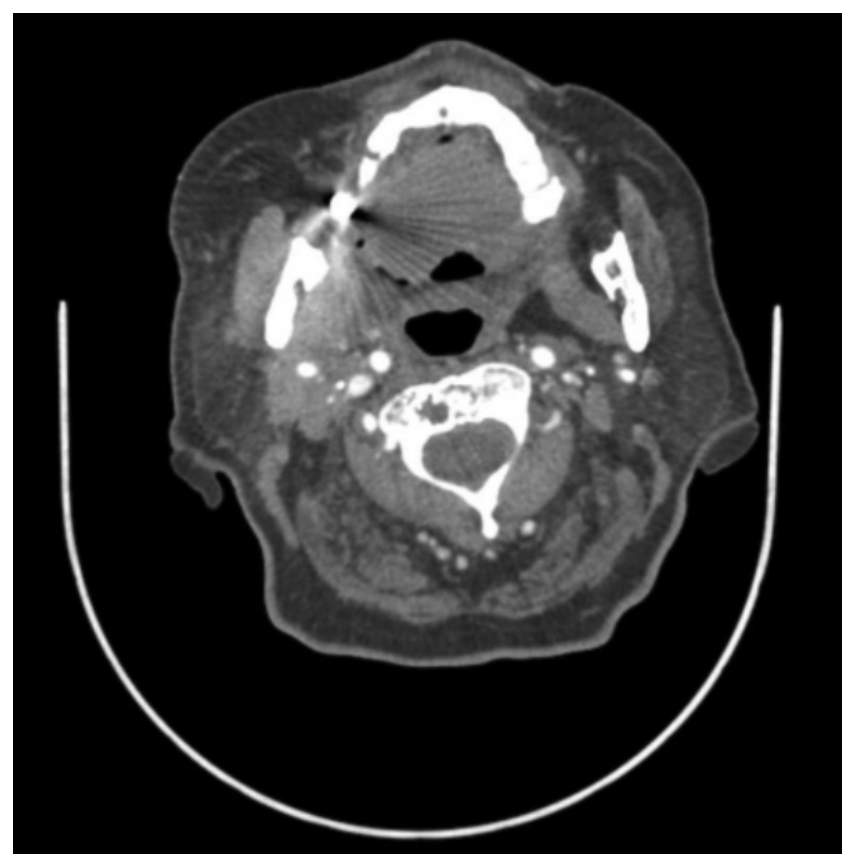

Figure 1. Axial and serial cross-sectional 1-mm thick cone beam computed tomography showed small radiolucent areas in close proximity to the third molar

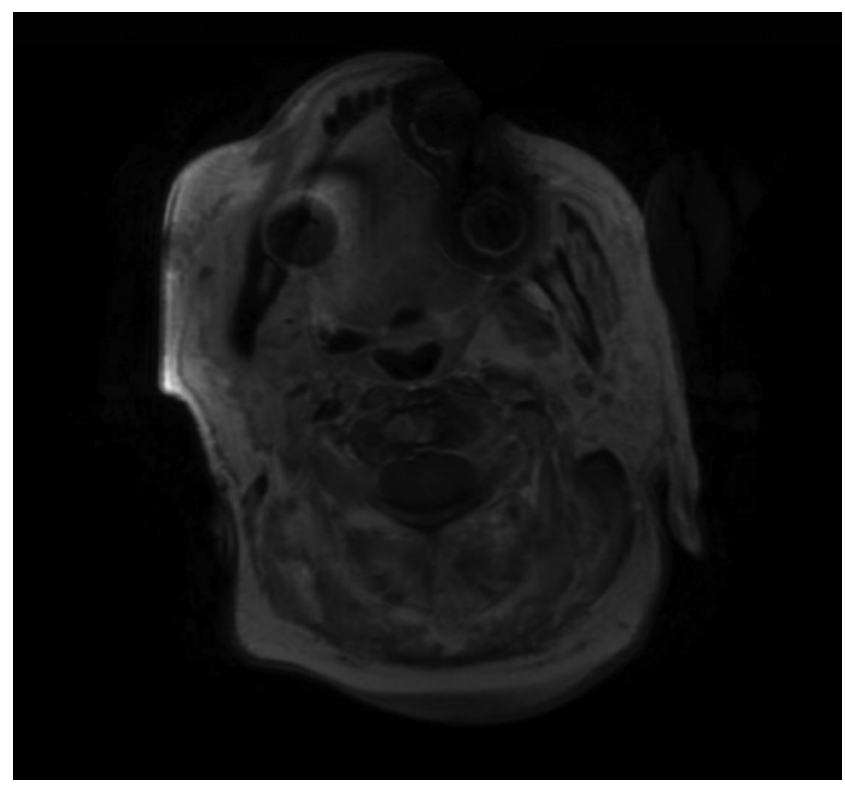

Figure 2. Magnetic resonance imaging provided the most accurate view of a chronic osteomyelitis lesion in the right mandibula 


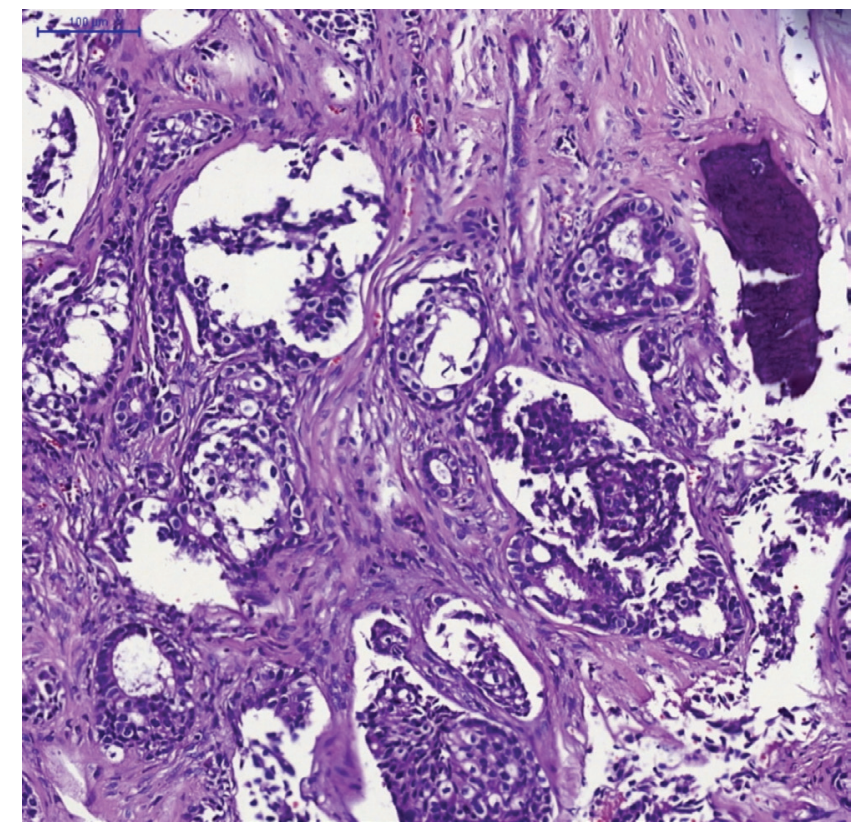

Figure 3. Adenocarcinoma. This tumor forms irregular-shaped and a cribriform glands with cytologically malignant cells exhibiting hiperchormatic nuclei in a fibroblastic stroma

\section{Discussion}

Metastasis is the spread of tumor cells from the primary tumor, their invasion of lymphovascular structures and survival in the circulation. The microvascular structure of the target organ provides space for metastatic tumor cells to which they can extravasate, invade and multiply in this target tissue. Angiogenesis is mandatory for tumor cell load of more than 2-3 mm for adequate oxygen and nutrient supply (2).

Diagnosis of oral cavity metastasis is an important challenge for the clinician due to the absence of pathognomonic signs and symptoms.

Breast cancer primarily metastasizes to the regional lymph nodes, bone, lungs, pleura, and liver. Bone is the most common site of recurrence of the breast cancer which can be lytic, sclerotic or mixed. In the present case, the mandibular lesion was of sclerotic type. Sclerotic bone metastases are more common in patients with prostate, bladder, medulloblastoma or bronchial carcinoid tumors.

Late metastasis is usually defined for lesions when they appear more than 5 years after the treatment of a primary malignant tumor. Late recurrence of some of the malignant tumors, such as renal cell carcinoma, breast cancer and malignant melanoma, has been well documented in the literature. Late recurrences are common in estrogen receptor (ER)-positive breast cancers. More than half of the recurrences of ER-positive breast cancers occur 5 years or later after the diagnosis and treatment of the primary tumor, and some cases may recur even more than 20 years after surgery. In contrast to ER-positive breast cancers, ERnegative breast cancer recurrences are more common in the first two years of treatment and these are rare 5 years after the treatment (3).

The present case was an ER-negative breast cancer and her mandibular lesion was diagnosed as late metastasis, occurring 16 years after the treatment of the primary tumor.

Oral region metastatic tumors are rare, comprising $1-3 \%$ of all malignant oral neoplasms. Malignant tumors of the breast, lung and kidney are the frequent primary sources. Metastatic tumors may occur in the oral soft tissues, jaw bones or both. Early detection of oral metastasis is critical, because the prognosis is usually poor. Most patients with the diagnosis of oral metastasis die within 1 year, while the 4-year survival rate is around $10 \%$. The survival in patients with lung cancers is longer than in patients with non-lung cancers. Most patients having oral metastasis have already developed generalized metastases; but, in numerous cases, mandibular metastasis may be the first sign of a primary tumor (4).

The mandible is the frequently involved location for metastases. Clinical findings of mandibular metastasis may mimic reactive or benign lesions or sometimes simple odontogenic infections. Pain, bony swelling with tenderness, hemorrhage, ulcer, tooth mobility, paresthesia, trismus and pathological fracture can be seen as clinical findings (5).

According to some meta-analysis about oral metastases, the gender distribution is either predominantly male or nearly equal. The primary location reported in the Western literature is the breast for women and lungs for men (6). In this paper, we reported a female patient.

Metastasis to the jaw bones is caused by the hematogenous pathway of the spread of the malignant tumor, and this needs the presence of a well-connected hematopoetically active bone marrow with the sinusoidal vascular spaces in the accumulation area of malignant cells. The posterior part of the mandible and focal osteoporotic bone marrow defects have been shown to be predisposed areas for metastatic tumor cells (7). Vascular changes in association with inflammatory process are thought to be responsible for oral metastasis. Chronic trauma to oral tissues has been shown to support the metastatic spread of malignant tumors into the oral cavity (8). A lymphatic system does not exist in the jaws and it is thought that metastasis occurs through bloodstream. A metastasis pathway to 
the maxillofacial area is Batson's plexus (vertebral venous plexus), which in some cases do not include the lungs, as in this patient. In another study with 55 cases, it was found that tooth extraction predated the detection of the metastasis (9). Therefore, the role of mucosal trauma, especially in particular improper dentures, poor oral hygiene and tooth extraction trauma, sharp teeth or restorations, should be further investigated in causation of oral metastasis.

The symptoms of oral/oropharyngeal metastasis are inequable and not pathognomonic. When oral lesions are present, biopsy is mandatory, especially in patients with known malignant disease, even if a benign condition is considered.

Paresthesia of the chin and lower lip is one of the important symptoms in metastatic disease. In the literature, it is defined as mental nerve neuropathy or NCS (10). Branches of the mandibular nerve, which are the inferior alveolar nerve and its branches like mental nerve, are associated with NCS. Since this nerve does not have motor fibers, NCS is a sensory neuropathy. Numbness of the teeth and mucosa may occur in addition to the lip and chin paresthesia. The main cause of NCS involves compression of nerve tissues by a tumor or perineural spread of a metastatic disease. Neoplasms, which are most frequently associated with NCS, are metastatic carcinomas of the mandible and lymphomas (8). Mostly, NCS is iatrogenic and is commonly caused by dental injury or anesthesia of the inferior alveolar nerve after placement of dental implants improperly. The other reasons are odontogenic or nonodontogenic tumors or cysts, acute or chronic osteomyelitis, and also systemic diseases such as Diabetes Mellitus, multiple sclerosis, sickle cell anemia, and human immunodeficiency virus infections (10). Our patient did not report paresthesia as the initial complaint, but it was observed that there was a change in the sensation of the lips and jaws in both intra-oral and extra-oral examinations. Thus, the presence of NCS should always alert the physician about the possibility of the presence of a primary or recurrent malignant neoplasm, particularly in cases of significant medical history.

NCS may be the first and only manifestation of malignancy. Therefore, it should be seen as malignancy unless proven otherwise and should never be ignored as a minor symptom. In a patient with a known malignancy, a detailed physical examination should be performed in the presence of a jaw, followed by panoramic radiography, CT or MRI, and a full body bone scan for further examination (11).

Osteosclerosis is the most striking radiologic pattern seen in primary chronic osteomyelitis which is usually encountered in adult cases. Osteosclerosis and osteolysis can be seen together and leading to a so called "mixed pattern" which is more frequent in younger patients. Bone expansion and "onion skin" periosteal reaction are some of the radiologic features associated with primary chronic osteomyelitis. Sequestration is not seen any case of primary osteomyelitis. Sclerotic form of primary chronic osteomyelitis may be confused with fibrous dysplasia or Paget's disease (12).

In our case, the sclerotic bone lesion was compatible with late metastasis from breast cancer and primary chronic osteomyelitis. Biopsy and histopathological examination were required because clinical and imaging findings were unspecific for definitive diagnosis. Histopathological examination revealed ER-negative breast cancer metastasis.

\section{Conclusion}

Otolaryngologists and dentists should include mandibular metastasis in the differential diagnosis during their general physical examination in patients with atypical symptoms, particularly if there is a history of previous breast cancer even many years after the initial diagnosis.

\section{Authorship Contributions}

Concept: D.H., O.Ü. Design: D.H., O.Ü. Data Collection or Processing: D.H., Ş.D. Analysis or Interpretation: O.Ü., Ş.D. Literature Search: D.H., Ş.D. Writing: D.H.

Conflict of Interest: No conflict of interest was declared by the authors.

Financial Disclosure: The authors declared that this study received no financial support.

\section{References}

1. Akinbami BO. Metastatic carcinoma of the jaws: a review of literature.Niger J Med 2009;18:139-42.

2. Hirshberg A, Leibovich P, Buchner A. Metastatic tumors to the jawbones: analysis of 390 cases. J Oral Pathol Med 1994;23:337-41.

3. Zhang XH, Giuliano M, Trivedi MV, Schiff R, Osborne CK. Metastasis dormancy in estrogen receptor-positive breast cancer. Clin Cancer Res 2013;19:6389-97.

4. Hirshberg A, Shnaiderman-Shapiro A, Kaplan I, Berger R. Metastatic tumours to the oral cavity: pathogenesis and analysis of 673 cases. Oral Oncol 2008;44:743-52.

5. Kumar G, Manjunatha B. Metastatic tumors to the jaws and oral cavity. J Oral Maxillofac Pathol 2013;17:71-5.

6. van der Waal RI, Buter J, van der Waal I. Oral metastases: report of 24 cases. Br J Oral Maxillofac Surg 2003;41:3-6.

7. Hashimoto N, Kurihara K, Yamasaki H, Ohba S, Sakai H, Yoshida S. Pathological characteristics of metastatic carcinoma in the human mandible. J Oral Pathol 1987;16:362-7. 
8. Lesnick JA, Zallen RD: Numb chin syndrome secondary to metastatic breast disease. J Colo Dent Assoc 1999;78:11-4.

9. Hirshberg A, Leibovich P, Horowitz I, Buchner A. Metastatic tumors to post-extraction site. J Oral Maxillofac Surg 1993;51:1334-7

10. Ryba F, Rice $S$, Hutchison IL: Numb chin syndrome: an ominous clinical sign. Br Dent J 2010;208:283-5.
11. Narendra H, Ray S. Numb chin syndrome as a manifestation of metastatic squamous cell carcinoma of esophagus. J Cancer Res Ther 2009;5:49Y51.

12. Curé JK, Vattoth S, Shah R. Radiopaque jaw lesions: an approach to the differential diagnosis. Radiographics 2012;32:1909-25. 